\title{
SIXI overexpression predicts poor prognosis and induces radioresistance through AKT signaling in esophageal squamous cell carcinoma
}

This article was published in the following Dove Press journal:

OncoTargets and Therapy

21 February 2017

Number of times this article has been viewed

\author{
Zheng $\mathrm{He}^{1,2}$ \\ Guang $\mathrm{Li}^{2}$ \\ Lingrong Tang ${ }^{2}$ \\ Yaming $\mathrm{Li}^{\prime}$ \\ 'Department of Nuclear Medicine, \\ ${ }^{2}$ Department of Radiation Oncology, \\ The First Hospital of China Medical \\ University, China Medical University, \\ Shenyang, China
}

\begin{abstract}
The Sineoculis homeobox homolog 1 (SIX1) protein has been found to be overexpressed in several human cancers. However, its expression pattern and biological roles in esophageal squamous cell carcinoma (ESCC) remain unexplored. This study examined the clinical significance of SIX1 in 119 ESCC tissues. It was found that SIX1 protein was upregulated in $36.9 \%$ (44/119) cases. SIX1 overexpression was an independent predictor for short survival of ESCC patients. siRNA knockdown and plasmid transfection were carried out in ESCC cell lines. SIX1 depletion inhibited cell growth, invasion, and colony formation, whereas its overexpression facilitated in vivo and in vitro cell growth, invasion, and colony formation. The apoptosis rate induced by X-ray irradiation was substantially increased by SIX1 knockdown in Eca-109 cells. Ectopic overexpression of SIX1 in TE-1 cells dramatically enhanced resistance to irradiation. Western blot analysis showed that SIX1 depletion downregulated cyclin E, matrix metalloproteinase-2 (MMP-2), Bcl-2 expression and upregulated Bim expression. SIX1 overexpression exhibited the opposite effect on these proteins. In addition, it was found that SIX1 could positively regulate extracellular signal-regulated kinase (ERK) and AKT signaling pathway. ERK inhibitor abolished the effect of SIX1 on MMP-2 expression. AKT inhibitor treatment blocked the role of SIX1 on anti-apoptotic protein Bcl-2. In conclusion, this study demonstrates that SIX1 overexpression predicts poor survival in ESCC patients and confers radioresistance through activation of AKT signaling pathways.
\end{abstract}

Keywords: SIX1, esophageal squamous cell carcinoma, ERK, AKT, radiosensitivity

\section{Introduction}

Esophageal squamous cell carcinoma (ESCC) is a common malignant tumor in China with rising incidence. Over the past decades, the overall survival for advanced ESCC remains poor. ${ }^{1}$ Tumor metastasis and poor response to chemotherapy and radiotherapy are the main causes of esophageal cancer induced mortality. ${ }^{2-4}$ Generally, ESCCs show an intermediate degree of radiosensitivity. It is effective in some patients. However, some patients show no response to this therapy and developed adverse effects. There are many factors that influence radioresistance in clinical practice. It remains important to identify new markers that can be used to predict radiosensitivity of esophageal cancers. ${ }^{5-8}$

Sineoculis homeobox homolog 1 (SIX1) is a member of SIX family proteins. SIX1 level remains high in the embryo and maintains progenitor cell survival. ${ }^{9-11}$ Decreased SIX1 induced apoptosis and loss of organ size. ${ }^{12}$ SIX1 remains at a low level in adult tissues, and its overexpression contributes to oncogenesis. ${ }^{13}$ SIX1 was found to be overexpressed in cervical, breast, pancreatic, and ovarian carcinomas. ${ }^{14-18}$ It was reported
Department of Nuclear Medicine, The First Hospital of China Medical University, Nanjing North St 155, Heping District, Shenyang, Liaoning I I000I,

China

Emailymli200I@I63.com (c)
hereby accept the Terms. Non-commercial uses of the work are permitted without any further permission from Dove Medical Press Limited, provided the work is properly attributed. For permission for commercial use of this work, please see paragraphs 4.2 and 5 of our Terms (https://www.dovepress.com/terms.php). 
that SIX1 upregulation induced cancer cell proliferation and epithelial-mesenchymal transition (EMT). ${ }^{19,20}$ These findings indicate that SIX1 may serve as an oncoprotein in human cancers. However, the clinical significance of SIX1 in human ESCC has not been explored. The association of SIX1 with cancer resistance to radiotherapy remains unclear.

This study examined SIX1 protein expression in ESCC specimens from 119 patients treated with radiotherapy and analyzed its correlation with prognosis. SIX1 expression was upregulated and downregulated in esophageal cancer cell lines and its roles in cell proliferation, invasion, and radiosensitivity were investigated. The potential molecular mechanism underlying its biological effects was also examined.

\section{Material and methods}

\section{Patients and specimens}

The study protocol was approved by the Institutional Review Board of China Medical University. A total of 119 tumor specimens were obtained from patients diagnosed with ESCC who underwent pre-therapeutic endoscopy examination. Patients enrolled in the study received definitive chemoradiotherapy between January 2006 and January 2014. Patients received chemoradiotherapy with cisplatin treatment and concomitant radiotherapy (total dose: 60 Gy over 6-7 weeks). The histological diagnosis was evaluated according to the WHO guidelines. Tumor staging was performed according to the TNM classification of the International Union Against Cancer. Clinical data were obtained from medical records. All the patients provided written informed consent for the use of tumor specimens and clinical data to be used for research.

\section{Immunohistochemical staining}

The formalin-fixed paraffin-embedded tissue sections were treated with xylene, graded alcohol and then antigen retrieval was performed in $0.01 \mathrm{M}$ citrate buffer. Hydrogen peroxide was used for blockage. Tissue sections were treated with goat serum for $20 \mathrm{~min}$. Sigma Prestige SIX1 antibody (1:300; Sigma-Aldrich Co., St Louis, MO, USA) was incubated with each section at $4^{\circ} \mathrm{C}$ overnight. EliVision plus and DAB kits from Maixin (Fuzhou, China) were used for immunohistochemical staining. Staining was performed according to manufacturer's procedure. All tumor slides were examined randomly by two independent pathologists. Staining in the nucleus was considered as SIX1 positive staining. Staining intensity was classified as: 0 : no staining, 1: moderate staining, and 2: strong staining and staining percentage was scored as: 1: 1\%-24\%, 2: 25\%-49\%, 3: 50\%-74\%, and
4: 75\%-100\%. Percentage score and intensity score were multiplied to give a final SIX1 score. Tumors with a final score $\geq 4$ were considered as SIX1 overexpressed tumors.

\section{Cell culture and transfection}

TE-1 and Eca-109 cell lines were obtained from American Type Culture Collection (Manassas, VA, USA). Cells were cultured in Dulbecco's Modified Eagle's Medium (Thermo Fisher Scientific, Waltham, MA, USA) containing 10\% fetal bovine serum (FBS; Gibco, Thermo Fisher Scientific).

SIX1 plasmid was obtained from Origene (Rockville, MD, USA). Lipofectamine 3000 transfection reagent was used for plasmid transfection (Thermo Fisher Scientific). The empty vector (pCMV6) was used as negative control. For siRNA transfection, SIX1 siGENOME SMARTpool siRNA and negative control siRNA were obtained from Dharmacon (Thermo Fisher Scientific). DharmaFECT 1 (Thermo Fisher Scientific) was used for siRNA transfection.

\section{X-ray treatment}

Plastic flasks with esophageal squamous cancer cells were treated with X-ray irradiation using a linear accelerator (Primus, Siemens, Germany) at a dose of 4 Gy. X-ray irradiation was performed when the cell density reached $80 \%$. After irradiation, the cells were harvested at the appropriate time points and processed for further analysis.

\section{Quantitative real-time PCR}

Real-time PCR was performed using SYBR Green master mix (TAKARA, Dalian, China). PCR was performed using 7500 Real-Time PCR System (Applied Biosystems, Foster city, CA, USA). $\beta$-Actin was used as the reference gene. The relative expression of target genes was calculated using the $2^{-\Delta \Delta \mathrm{Ct}}$ method. The primer sequences are as follows: SIX1 forward, 5’ AAGGAGAAGTCGAGGGGTGT 3', SIX1 reverse, 5' TGCTTGTTGGAGGAGGAGTT 3'; $\beta$-actin forward, 5' ATAGCACAGCCTGGATAGCAACGTAC 3', $\beta$-actin reverse, 5' CACCTTCTACAATGAGCTGCGTGTG 3'.

\section{Western blot analysis}

Total proteins from cells were extracted in radioimmunoprecipitation assay lysis buffer and quantified using the Bradford method. Protein samples were transferred to polyvinylidene fluoride (PVDF) membranes (EMD Millipore, Billerica, MA, USA) and incubated overnight at $4{ }^{\circ} \mathrm{C}$ with primary antibody against SIX1 (1:1,000; Sigma-Aldrich Co.), p-AKT, Bim, Bcl-2, caspase-3, cleaved caspase-3, p-extracellular signal-regulated kinase ( $\mathrm{p}-\mathrm{ERK}$ ), matrix metalloproteinase-2 
(MMP-2), cyclin E (1:1,000, Cell Signaling Technology, Boston, MA, USA), and GAPDH (1:1,000; Santa Cruz Biotechnology, Santa Cruz, CA, USA). After incubation with peroxidase-coupled secondary antibody $(1: 2,000$, Santa Cruz Biotechnology) at $37^{\circ} \mathrm{C}$ for $2 \mathrm{~h}$, target proteins on PVDF membrane were visualized using an enhanced chemiluminescence kit (Pierce, Rockford, IL, USA) and obtained using DNR Imaging System (DNR, Jerusalem, Israel).

\section{Colony formation and MTT assays}

For colony formation assay, cells were transfected for $48 \mathrm{~h}$ and plated into three $6 \mathrm{~cm}$ cell culture dishes (1,000 cells). Cells were incubated for 2 weeks in medium. Plates were washed with phosphate-buffered saline (PBS) and stained with Giemsa (Beyotime Biotechnology, Shanghai, China). The number of colonies with more than 50 cells was counted. The colonies were manually counted using a microscope.

For MTT assay, $24 \mathrm{~h}$ after transfection, cells were plated in 96-well plates at a concentration of $\sim 2,000$ cells per well and cultured for 5 days. For quantitation of cell proliferation rate, $20 \mu \mathrm{L}$ of $5 \mathrm{mg} / \mathrm{mL}$ MTT (thiazolyl blue) solution was added to each well and incubated for $4 \mathrm{~h}$ at $37^{\circ} \mathrm{C}$. The medium was removed from each well and $150 \mu \mathrm{L}$ of dimethyl sulfoxide was added to the well. The plate was measured at $490 \mathrm{~nm}$.

\section{Mouse xenograft study}

The use of animals was approved by the Animal Care and Ethics Committee of China Medical University and was in line with the Guide for Care and Use of Laboratory Animals of China Medical University. Female athymic nude BALB/c mice (4 weeks old) were purchased from Shanghai SLAC Laboratory Animals Ltd. (Shanghai, China). The mice were housed in the Laboratory Animal Center of China Medical University. Selection of stable TE-1-SIX1 cell line was accomplished with G418 (Sigma-Aldrich Co.) at a concentration of $0.3 \mathrm{mg} / \mathrm{mL}$. A xenograft model was established by subcutaneous right armpit injections of stable cell lines $\left(5 \times 10^{6}\right)$. Tumor size was measured every week. Following 4 weeks' growth, animals were sacrificed and xenograft tumors were removed.

\section{Apoptosis detection}

Cell apoptosis detection was performed with Annexin V/ propidium iodide (PI) double staining. Briefly, $48 \mathrm{~h}$ after transfection, cells were harvested by $0.25 \%$ trypsin, washed twice with cold PBS, followed by being resuspended in $250 \mu \mathrm{L}$ of binding buffer. Staining solution containing
Annexin V/fluorescein isothiocyanate and PI was added in the cell suspension. After incubation in the dark for $30 \mathrm{~min}$, the cells were analyzed by a FACS Calibur flow cytometer (Becton-Dickinson, Franklin Lakes, NJ, USA).

\section{Matrigel invasion assay}

Matrigel cell invasion assay was performed using a 24-well transwell chamber (Corning Inc., Corning, NY, USA). The transwell chambers were coated with $20 \mu \mathrm{L}$ matrigel (1:3). Transfected cells were trypsinized and suspended in $100 \mu \mathrm{L}$ of medium without serum, which was transferred to the upper chamber. Culture medium $(600 \mu \mathrm{L})$ with $15 \%$ FBS was added to the lower chamber. After overnight incubation, the non-invading cells on the upper membrane surface were removed and the cells that passed through the filter were fixed and stained with hematoxylin. The number of cells that passed through the membrane was counted using a microscope. This experiment was performed in triplicate.

\section{Statistical analysis}

SPSS 12 for Windows (SPSS Inc., Chicago, IL, USA) was used for all statistical analyses. A $\chi^{2}$ test was used to examine possible correlations between SIX1 expression and clinicopathologic factors. Student's $t$-test was used to compare other data. $P<0.05$ was considered to indicate statistical significance.

\section{Results \\ SIXI correlated with poor prognosis in esophageal cancer patients}

SIX1 protein was examined in 119 cases of ESCC tissues (Figure 1). SIX1 expression was weak/negative in normal esophageal mucosa epithelial tissues. Nuclear staining with a final score $\geq 4$ was considered as SIX1 overexpression. SIX1 overexpression was observed in 44 of 119 ESCC tissues. The correlation of SIX1 with clinical factors was analyzed. As shown in Table 1, no significant association was found between SIX1 and age, gender, and TNM stage. The correlation of SIX1 with prognosis of ESCC patients was also analyzed. Kaplan-Meier survival analysis showed a significantly lower overall survival (after chemoradiotherapy) in patients with positive SIX1 (mean survival: 19.2 months) compared with those with negative expression (mean survival: 30.1 months $)(P=0.0026$, log-rank test; Figure 1). Cox regression model was used to predict prognostic factors. As shown in Table 2, SIX1 expression $(P=0.0074)$, gender $(P=0.0252)$, and T stage $(P=0.0016)$ were independent prognostic predictor factors for overall patient survival. 

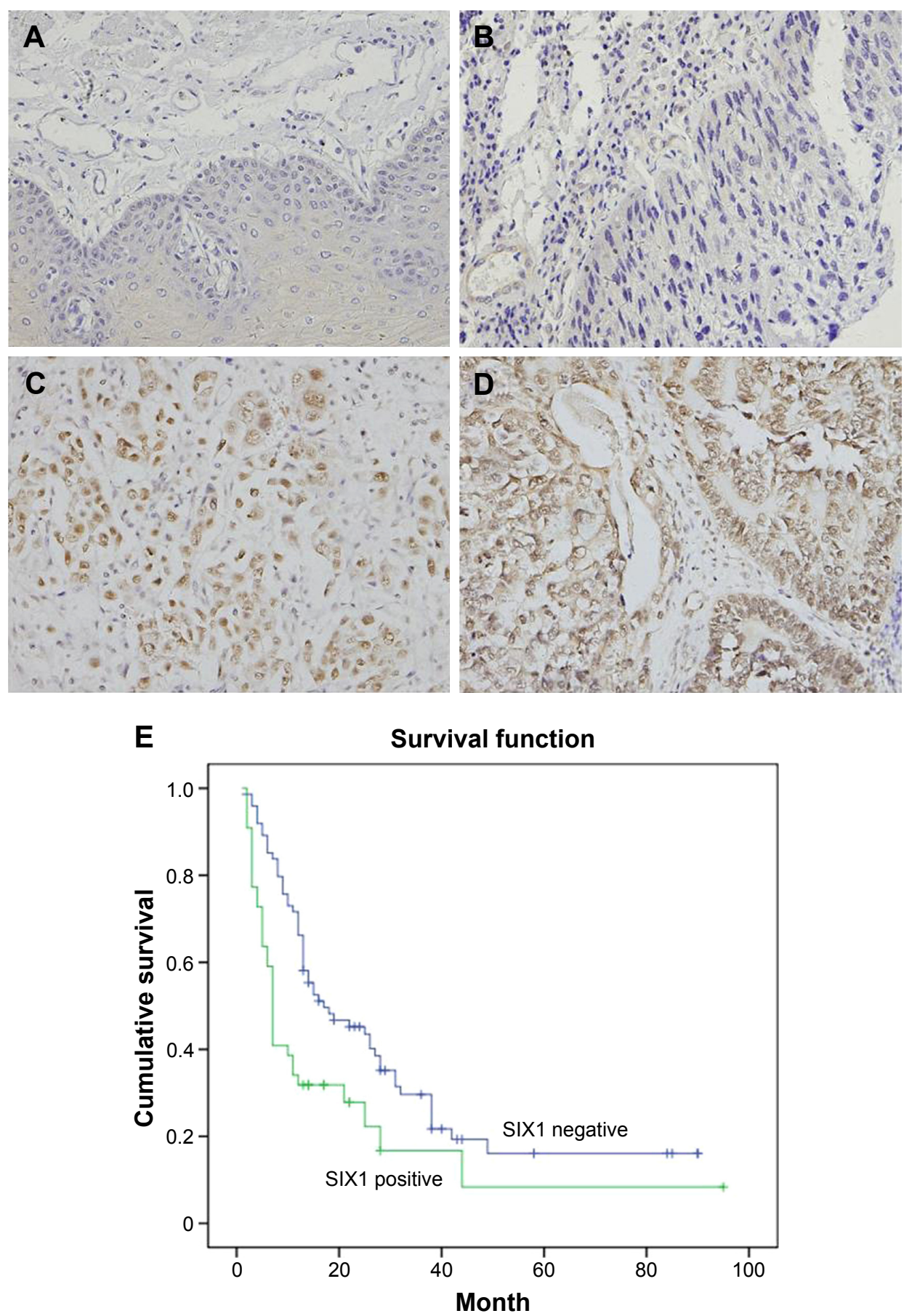

Figure I Expression of SIXI protein in esophageal squamous cell carcinoma (ESCC) tissues.

Notes: (A) Negative SIXI expression in normal esophageal squamous mucosa tissues. (B) Negative SIXI expression in a case of stage I, grade I ESCC tissue. (C) Positive nuclear staining of SIXI in a case of grade 2 ESCC. (D) Positive nuclear and cytoplasmic expression in a case of stage 3 ESCC tissue. (E) Survival analysis of SIXI in ESCC tissues. Magnification, 400x.

\section{SIXI promotes esophageal cancer in vivo and in vitro cell proliferation, invasion, and radioresistance}

Protein expression of SIX1 was examined by Western blot in esophageal cancer cell lines. It was found that Eca-109 cell line had high endogenous SIX1 expression while TE-1 cell line showed low endogenous SIX1 expression (Figure 2A). SIX1 transfection and siRNA knockdown were performed. As shown in Figure 2B, plasmid significantly upregulated SIX1 protein and mRNA in TE-1 cells. The efficiency of siRNA knockdown was also confirmed. MTT demonstrated that SIX1 transfection facilitated the cell proliferation rate 
Table I Distribution of SIXI status in esophageal carcinoma according to clinicopathological characteristics

\begin{tabular}{|c|c|c|c|c|}
\hline Characteristics & $\begin{array}{l}\text { Number } \\
\text { of patients }\end{array}$ & $\begin{array}{l}\text { SIXI low } \\
\text { expression }\end{array}$ & $\begin{array}{l}\text { SIXI over- } \\
\text { expression }\end{array}$ & $P$-value \\
\hline \multicolumn{4}{|l|}{ Age } & 0.7508 \\
\hline$<60$ & 40 & 26 & 14 & \\
\hline$\geq 60$ & 79 & 49 & 30 & \\
\hline \multicolumn{4}{|l|}{ Gender } & 0.746 \\
\hline Female & 17 & 14 & 3 & \\
\hline Male & 102 & 61 & 41 & \\
\hline \multicolumn{4}{|l|}{ TNM stage } & 0.2964 \\
\hline I+II & 22 & 16 & 6 & \\
\hline III + IV & 97 & 59 & 38 & \\
\hline \multicolumn{4}{|l|}{ T stage } & 0.9682 \\
\hline TI-3 & 43 & 27 & 16 & \\
\hline $\mathrm{T} 4$ & 76 & 48 & 28 & \\
\hline \multicolumn{4}{|c|}{ Lymph node metastasis } & 0.7225 \\
\hline Negative & 107 & 68 & 39 & \\
\hline Positive & 12 & 7 & 5 & \\
\hline \multicolumn{4}{|c|}{ Distant metastasis } & 0.2545 \\
\hline Negative & 112 & 72 & 40 & \\
\hline Positive & 7 & 3 & 4 & \\
\hline
\end{tabular}

Abbreviation: TNM, tumor-node-metastasis.

in TE-1 cell line, while its siRNA blocked proliferation in Eca-109 cell line (Figure 3A). Colony formation assay showed similar results. SIX1 plasmid significantly promoted colony formation ability while its siRNA inhibited the same (Figure 3B) $(P<0.05)$. To explore the role of SIX1 on cell invasion, transwell assay was carried out. Figure $3 \mathrm{C}$ shows significant reduction of the invading ability in Eca-109 cells after SIX1 depletion. SIX1 plasmid upregulated the invading ability of TE-1 cells $(P<0.05)$. To investigate the effects of SIX1 in vivo, stable SIX1 overexpressed TE-1 cell line was established by G418 selection. These cells were delivered by subcutaneous injection into the flanks of mice $(n=3)$. As shown in Figure 3D, SIX1-transfected TE-1 cells showed increased growth speed compared with empty vector.

Radiotherapy is widely applied to ESCC and has a central role in the therapeutic strategy against ESCC. To explore the roles of SIX1 in the radiotherapy response of ESCC cells, apoptosis rate and caspase-3 cleavage of TE-1 and Eca-109 cells induced by irradiation were examined (Figure 4A). After

Table 2 Multivariate analysis for predictive factors in patients with esophageal carcinoma (Cox regression model)

\begin{tabular}{lll}
\hline Factors & Hazard ratio $(95 \% \mathrm{CI})$ & P-value \\
\hline SIXI & $1.870(1.183-2.956)$ & 0.0074 \\
Gender & $2.537(1.123-5.732)$ & 0.0252 \\
Age & $0.932(0.567-1.53 \mathrm{I})$ & 0.7799 \\
T stage & $1.906(1.276-2.874)$ & 0.0016 \\
Nodal status & $0.895(0.603-1.329)$ & 0.5833 \\
Distal metastasis & $1.233(0.523-2.907)$ & 0.6319 \\
\hline
\end{tabular}

Abbreviation: $\mathrm{Cl}$, confidence interval.
A

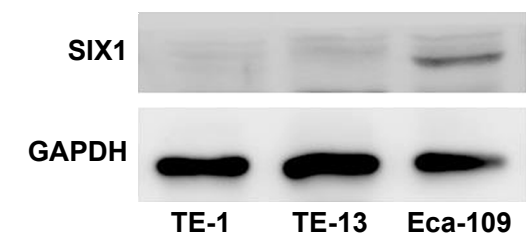

B
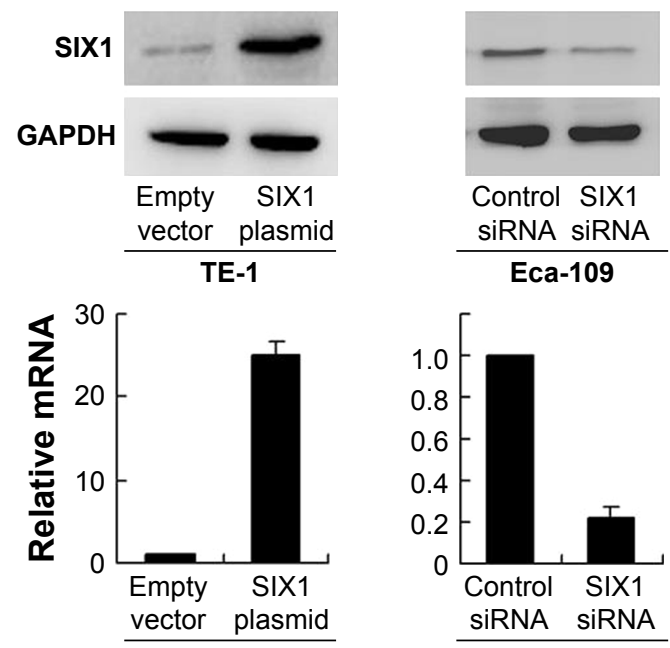

TE-1

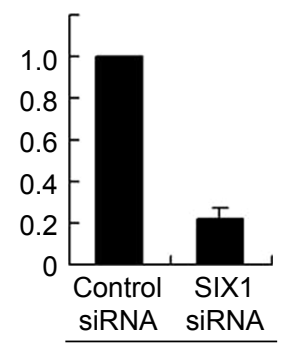

Eca-109

Figure 2 Expression of SIXI in esophageal squamous cell carcinoma cell lines and its transfection and knockdown efficiency.

Notes: (A) Western blot showed that SIXI protein was high in Eca-I09 cell line and low in TE-I cell line. (B) Western blot and real-time PCR analyses showed that SIXI transfection in TE-I cell line increased its protein and mRNA expression. SIXI siRNA treatment in Eca- 109 cell line decreased its protein and mRNA expression.

4 Gy X-ray treatment, a significant decrease in apoptosis rate was seen in TE-1 cells transfected with SIX1 compared with control cells. In contrast, transfection with SIX1 siRNA increased the apoptosis rate in Eca-109 cell line. Consistently, suppression of SIX1 in Eca-109 cells induced significant increases in cleaved caspase-3 in cells treated with 4 Gy irradiation. Overexpression of SIX1 decreased the level of caspase-3 cleavage (Figure 4B).

\section{SIXI regulates cyclin E, MMP-2, Bcl-2, and Bim}

Next, the change of cell cycle, invasion, and apoptosis related proteins were studied. The results showed that SIX1 transfection upregulated cyclin E and MMP-2 expression, while SIX1 depletion showed the opposite effects (Figure 4B). These data suggested that SIX1 regulates esophageal cancer proliferation and invasion through regulation of cyclin $\mathrm{E}$ and MMP-2. In addition, the expression of apoptosis related protein was examined including Bcl-2 and Bim. As shown in Figure 4B, SIX1 transfection in TE-1 cells upregulated Bcl-2 and downregulated Bim expression. SIX1 siRNA depletion in Eca-109 cells downregulated Bcl-2 and upregulated Bim protein. 
A

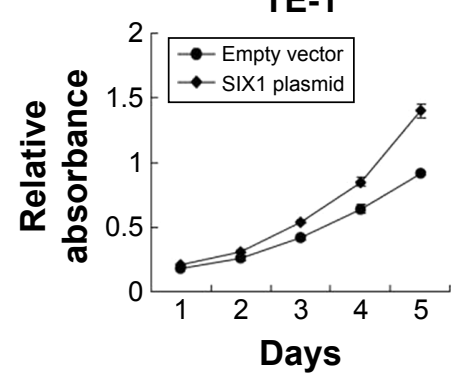

TE-1

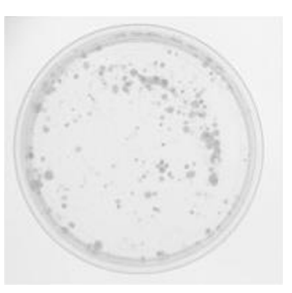

Empty vector

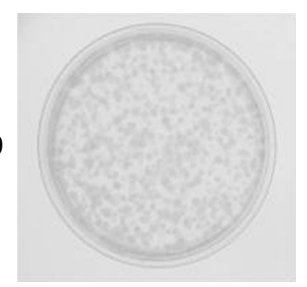

Negative siRNA

C

TE-1

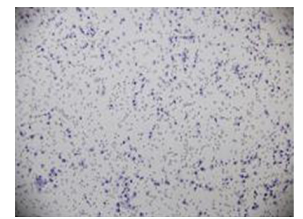

Empty vector

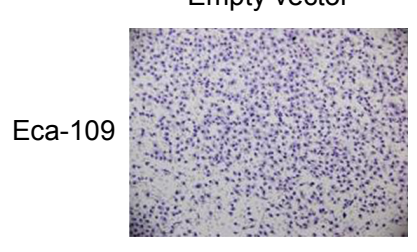

Negative siRNA

B

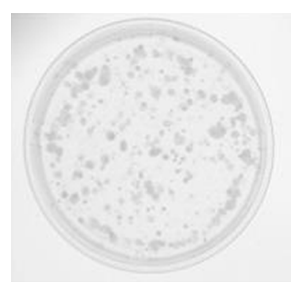

SIX1 plasmid

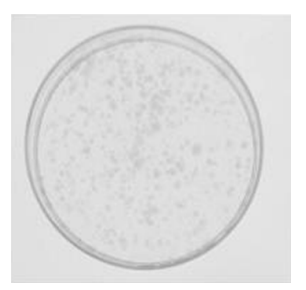

SIX1 SiRNA

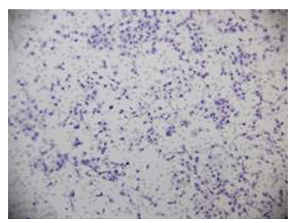

SIX1 plasmid

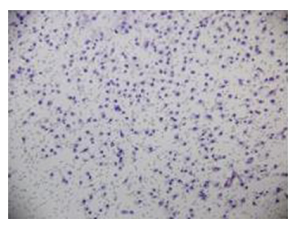

SIX1 siRNA

\section{Eca-109}

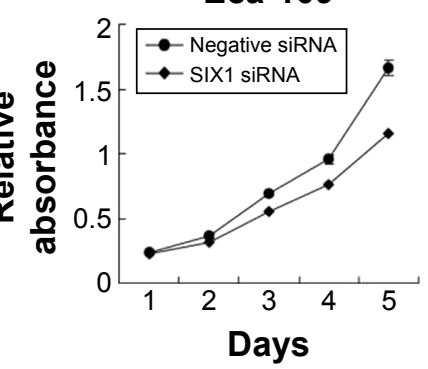

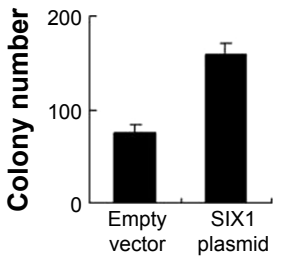
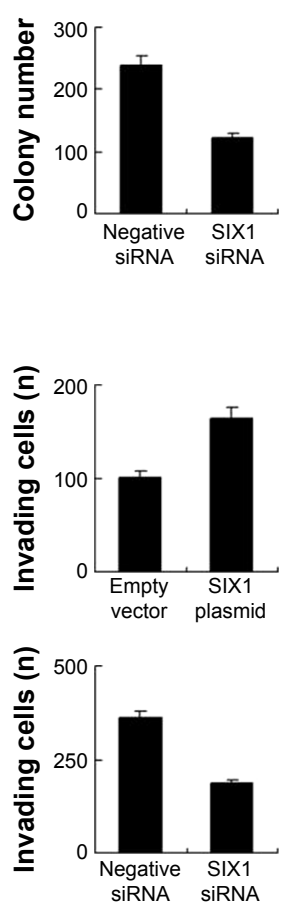

D
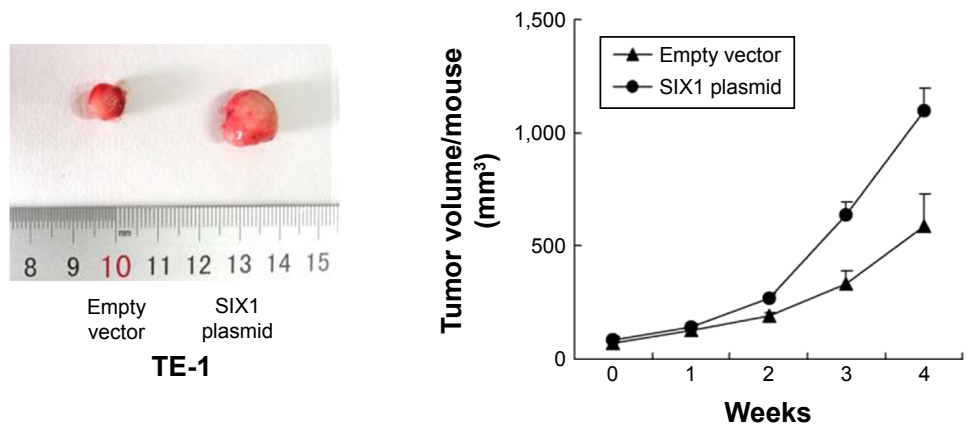

Figure 3 SIXI promotes proliferation and invasion in esophageal squamous cell carcinoma cell lines.

Notes: (A) MTT assay showed that SIXI transfection upregulated cell proliferation rate in TE-I cell line and SIXI siRNA downregulated the cell proliferation rate in Eca-I09 cell line. (B) Colony formation assay showed that SIXI transfection increased while its depletion decreased colony formation ability. (C) Matrigel invasion assay showed that SIXI overexpression promoted the invading ability of TE-I cell line while its depletion inhibited invasion of Eca-I09 cells. (D) Nude mice bearing subcutaneous cell xenografts were sacrificed after 4 weeks, tissues were completely removed, and photographs were taken. Tumor volume of xenograft was significantly upregulated when injected with SIXI overexpressed cells compared with control. 
A

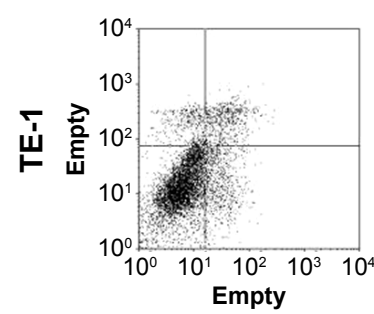

Empty vector

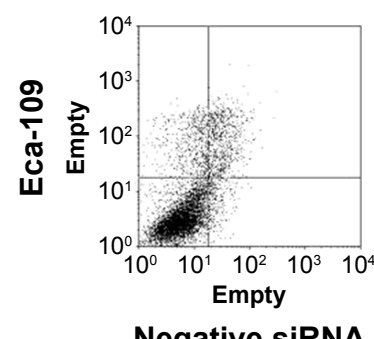

Negative siRNA

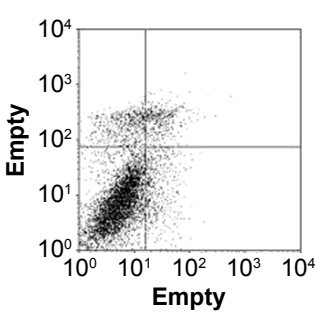

SIX1 plasmid

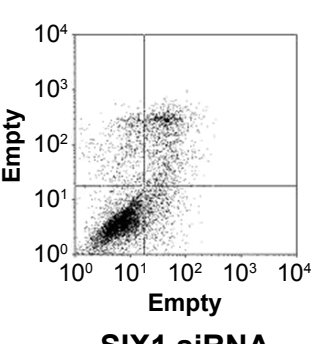

SIX1 SIRNA
B

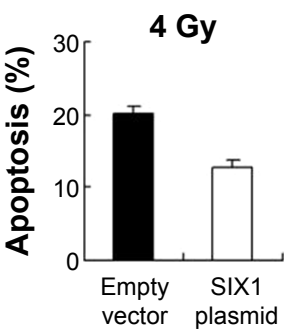

$$
\text { Cyclin }
$$

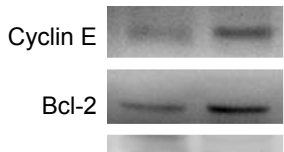

Eca-109

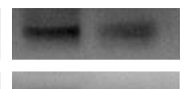

Bim
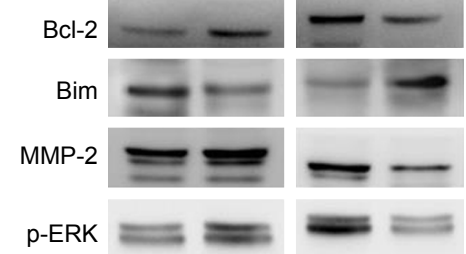

p-AKT
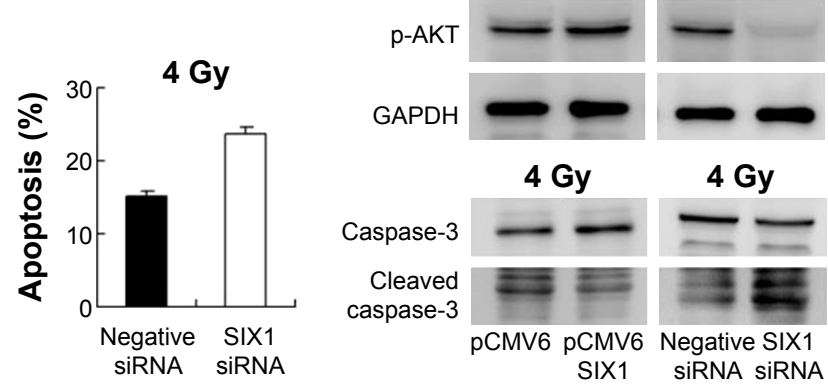

Figure 4 SIXI regulates radiosensitivity and ERK/AKT signaling.

Notes: (A) AnnexinV/propidium iodide analysis showed, after 4 Gy X-ray treatment, a significant decrease in apoptosis rate in TE-I cells transfected with SIXI. Transfection with SIXI siRNA increased the apoptosis rate in Eca-109 cell line. (B) SIXI transfection upregulated cyclin E, matrix metalloproteinase-2 (MMP-2), Bcl-2, P-extracellular signal-regulated kinase (p-ERK), and p-AKT and downregulated Bim and cleaved caspase-3. SIXI depletion showed the opposite effects.

\section{SIXI regulates MMP-2 through ERK signaling and $\mathrm{Bcl}-2$ through AKT signaling} To explore the potential mechanism of SIX1 induced invasion and radioresistance, several signaling pathways which may be involved in the regulation of irradiation induced apoptosis were observed. Mitogen-activated protein kinase/ ERK signaling pathways and AKT signaling pathway were studied and it was found that SIX1 overexpression significantly upregulated both ERK and AKT phosphorylation. Previous reports indicated that activation of ERK resulted in MMP-2 production. ${ }^{21}$ To confirm this, ERK inhibitor PD98059 $(20 \mu \mathrm{M}, 6 \mathrm{~h})$ was used to treat TE-1 cells. As shown in Figure 5A, inhibition of ERK signaling blocked the role of SIX1 on MMP-2 production. AKT activation has
A

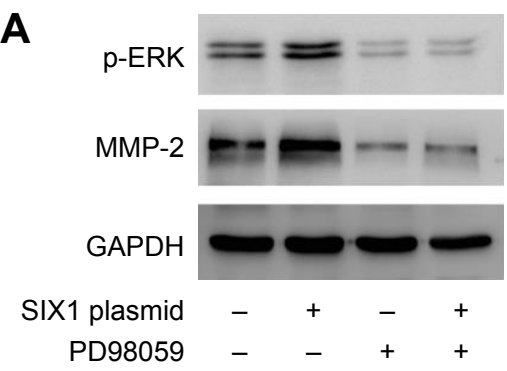

B

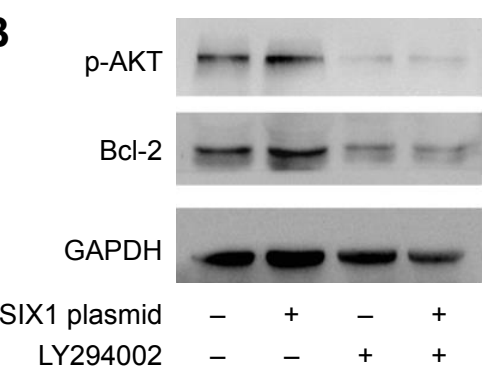

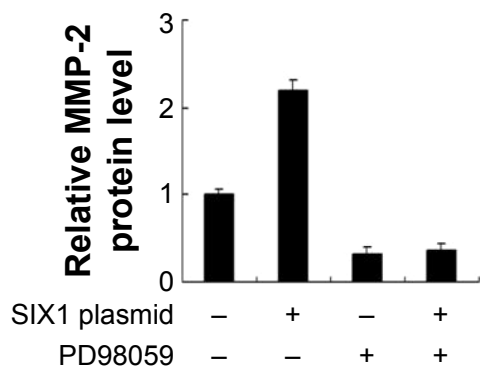

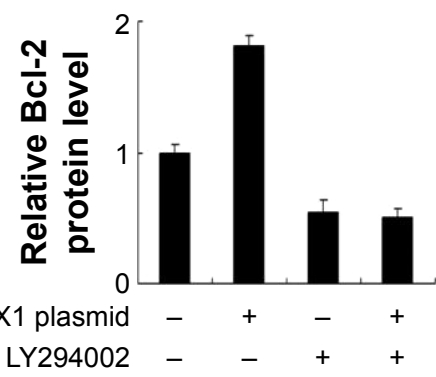

Figure 5 SIXI regulates matrix metalloproteinase-2 (MMP-2) and Bcl-2 through extracellular signal-regulated kinase (ERK) and AKT signaling.

Notes: (A) ERK inhibitor PD98059 $(20 \mu \mathrm{M})$ was used to treat TE-I cell line. Inhibition of ERK signaling reduced p-ERK expression. PD98059 also blocked the role of SIXI on MMP-2 production. Quantification of protein expression was performed using ImageJ software. (B) LY294002 (I0 $\mu$ M) was used to block AKT signaling in TE-I cell line. LY294002 treatment could block SIXI induced change of Bcl-2. Quantification of protein expression was performed using Image software. 
been implicated in Bcl-2 upregulation and development of chemoradioresistance in ESCC. ${ }^{22}$ To confirm that SIX1 could induce the AKT/Bcl-2 pathway, AKT inhibitor LY294002 (10 $\mu \mathrm{M}, 6 \mathrm{~h})$ was applied to TE-1 cells together with SIX1 plasmid. As shown in Figure 5B, the AKT inhibitor abolished the role of SIX1 on Bcl-2 upregulation.

\section{Discussion}

SIX1 overexpression has been reported in several human cancers such as breast cancer, cervical cancer, ovarian cancer, gastric cancer, and pancreatic cancer, which leads to cancer cell proliferation, invasion, and metastasis. ${ }^{16-18,20}$ SIX1 upregulation leads to EMT through activation of zinc-finger E-box binding homeobox $1 .{ }^{23}$ However, the involvement of SIX1 in human ESCC remains unexplored.

The present study demonstrated that SIX1 overexpression correlated with poor survival and serves as an independent prognostic factor in ESCC patients treated with radiotherapy. In addition, SIX1 overexpression increased in vivo and in vitro proliferation in TE-1 cells, with upregulation of invading ability, while its depletion inhibited Eca-109 cell growth and invasion. These data are in accordance with previous reports, indicating that SIX1 status might reflect malignant phenotype and poor treatment response of ESCC.

When exploring its possible underlying mechanism, it was found that SIX1 overexpression upregulated cyclin E and MMP-2 protein, suggesting SIX1 supports cell proliferation through cyclin E and induces cell invasion through MMP-2. MMP-2 is an important mediator of cancer cell invasion in various cancers including ESCC. ${ }^{24-26}$ ERK activation is reported to induce MMP-2 production through activation of AP-1 transcription factor. ${ }^{21}$ It was found that SIX1 overexpression activated ERK phosphorylation. This study also demonstrated that SIX1 induced MMP-2 could be blocked by ERK inhibitor, suggesting SIX1 induces ESCC cell invasion through modulation of ERK/MMP-2 signaling.

Clinically, radiotherapy is widely used for ESCC patients with locally advanced disease. The role of SIX1 on chemoresistance has been reported before in breast cancer cells. ${ }^{27,28}$ However, its involvement in radioresistance remains unexplored. This study showed that esophageal cancer cells treated with SIX1 siRNA showed a better response to radiation therapy than control cells, while cells with SIX1 overexpression showed resistance to irradiation. These results suggest that SIX1 is at least one of the proteins that regulates cell death after irradiation.

Cancer radiosensitivity involves multiple proteins; some researchers attributed irradiation effectiveness to apoptosis. ${ }^{29-31}$ A panel of relevant targets was examined and it was found that $\mathrm{Bcl}-2$, a potent apoptosis inhibitor, was upregulated by SIX1 overexpression. SIX1 negatively regulated apoptosis-inducing factor Bim. Bcl-2 is reported to be involved in the radioresistance of various cancers including ESCC, ${ }^{32-35}$ whereas Bim functions as a promoter of apoptosis by inducing cytotoxic signals. ${ }^{36}$ Thus, SIX1 suppresses apoptosis through upregulation of $\mathrm{Bcl}-2$ and downregulation of Bim in esophageal cancer cells treated with irradiation.

The potential signaling pathway involved in the regulation of $\mathrm{Bcl}-2 / \mathrm{Bim}$ proteins was investigated. AKT pathway has been reported to be involved in the development of radioresistance and Bcl-2 upregulation. ${ }^{37-40}$ The results showed that SIX1 overexpression upregulated AKT signaling. Treatment of AKT inhibitor abolished the effect of SIX1 on Bcl-2 upregulation, indicating that AKT activation mediated, at least partly, SIX1 stimulated Bcl-2 upregulation and radioresistance.

In summary, it is demonstrated that SIX1 overexpression is a novel predictor of ESCC aggressiveness and an independent prognostic factor for ESCC patients treated with chemoradiotherapy. Targeting SIX1 might be a novel strategy to improve therapeutic effects in ESCC patients.

\section{Disclosure}

The authors report no conflicts of interest in this work.

\section{References}

1. Siegel R, Ma J, Zou Z, Jemal A. Cancer statistics, 2014. CA Cancer J Clin. 2014;64:9-29.

2. Xia X, Du R, Zhao L, Sun W, Wang X. Expression of AEG-1 and microvessel density correlates with metastasis and prognosis of oral squamous cell carcinoma. Hum Pathol. 2014;45:858-865.

3. Huang WC, Chan SH, Jang TH, et al. miRNA-491-5p and GIT1 serve as modulators and biomarkers for oral squamous cell carcinoma invasion and metastasis. Cancer Res. 2014;74:751-764.

4. Chang KP, Wang CL, Kao HK, et al. Overexpression of caldesmon is associated with lymph node metastasis and poorer prognosis in patients with oral cavity squamous cell carcinoma. Cancer. 2013;119: 4003-4011.

5. Rochigneux P, Resbeut M, Rousseau F, et al. Radio(chemo)therapy in elderly patients with esophageal cancer: a feasible treatment with an outcome consistent with younger patients. Front Oncol. 2014;4:100.

6. Zingg U, Montani M, Frey DM, Dirnhofer S, Went P, Oertli D. Influence of neoadjuvant radio-chemotherapy on tumor-infiltrating lymphocytes in squamous esophageal cancer. Eur J Surg Oncol. 2009;35: $1268-1272$.

7. Xie L, Song X, Yu J, et al. Fractionated irradiation induced radio-resistant esophageal cancer EC109 cells seem to be more sensitive to chemotherapeutic drugs. J Exp Clin Cancer Res. 2009;28:68.

8. Rades D, Schulte R, Yekebas EF, Homann N, Schild SE, Dunst J. Radio(chemo)therapy plus resection versus radio(chemo)therapy alone for the treatment of stage III esophageal cancer. Strahlenther Onkol. 2007;183:10-16. 
9. Liu Y, Chakroun I, Yang D, et al. Six 1 regulates MyoD expression in adult muscle progenitor cells. PLoS One. 2013;8:e67762.

10. Nord H, Nygard Skalman L, von Hofsten J. Six1 regulates proliferation of Pax7-positive muscle progenitors in zebrafish. J Cell Sci. 2013; 126:1868-1880.

11. Ikeda K, Kageyama R, Suzuki Y, Kawakami K. Six1 is indispensable for production of functional progenitor cells during olfactory epithelial development. Int J Dev Biol. 2010;54:1453-1464.

12. Chen B, Kim EH, Xu PX. Initiation of olfactory placode development and neurogenesis is blocked in mice lacking both Six 1 and Six 4 . Dev Biol. 2009;326:75-85.

13. Kumar JP. The sine oculis homeobox (SIX) family of transcription factors as regulators of development and disease. Cell Mol Life Sci. 2009;66:565-583.

14. Coletta RD, Christensen K, Reichenberger KJ, et al. The Six1 homeoprotein stimulates tumorigenesis by reactivation of cyclin A1. Proc Natl Acad Sci U S A. 2004;101:6478-6483.

15. Reichenberger KJ, Coletta RD, Schulte AP, Varella-Garcia M, Ford HL. Gene amplification is a mechanism of Six 1 overexpression in breast cancer. Cancer Res. 2005;65:2668-2675.

16. Zheng XH, Liang PH, Guo JX, et al. Expression and clinical implications of homeobox gene Six 1 in cervical cancer cell lines and cervical epithelial tissues. Int J Gynecol Cancer. 2010;20:1587-1592.

17. Behbakht K, Qamar L, Aldridge CS, et al. Six 1 overexpression in ovarian carcinoma causes resistance to TRAIL-mediated apoptosis and is associated with poor survival. Cancer Res. 2007;67:3036-3042.

18. Li Z, Tian T, Lv F, et al. Six1 promotes proliferation of pancreatic cancer cells via upregulation of cyclin D1 expression. PLoS One. 2013 8:e59203.

19. Smith AL, Iwanaga R, Drasin DJ, et al. The miR-106b-25 cluster targets Smad7, activates TGF-beta signaling, and induces EMT and tumor initiating cell characteristics downstream of Six 1 in human breast cancer. Oncogene. 2012;31:5162-5171.

20. Radisky DC. Defining a role for the homeoprotein Six1 in EMT and mammary tumorigenesis. J Clin Invest. 2009;119:2528-2531.

21. Dong QZ, Wang Y, Tang ZP, et al. Derlin-1 is overexpressed in nonsmall cell lung cancer and promotes cancer cell invasion via EGFRERK-mediated up-regulation of MMP-2 and MMP-9. Am J Pathol. 2013;182:954-964.

22. Chen J, Yang H, Wen J, et al. NHE9 induces chemoradiotherapy resistance in esophageal squamous cell carcinoma by upregulating the $\mathrm{Src} /$ Akt/beta-catenin pathway and Bcl-2 expression. Oncotarget. 2015; 6:12405-12420.

23. Ono H, Imoto I, Kozaki K, et al. SIX1 promotes epithelial-mesenchymal transition in colorectal cancer through ZEB1 activation. Oncogene. 2012;31:4923-4934.

24. Wang F, Qi Y, Li X, He W, Fan QX, Zong H. HDAC inhibitor trichostatin A suppresses esophageal squamous cell carcinoma metastasis through HADC2 reduced MMP-2/9. Clin Invest Med. 2013;36: E87-E94.
25. Li Y, Ma J, Guo Q, et al. Overexpression of MMP-2 and MMP-9 in esophageal squamous cell carcinoma. Dis Esophagus. 2009;22: 664-667.

26. Samantaray S, Sharma R, Chattopadhyaya TK, Gupta SD, Ralhan R. Increased expression of MMP-2 and MMP-9 in esophageal squamous cell carcinoma. J Cancer Res Clin Oncol. 2004;130:37-44.

27. Armat M, Oghabi Bakhshaiesh T, Sabzichi M, et al. The role of Six1 signaling in paclitaxel-dependent apoptosis in MCF-7 cell line. Bosn J Basic Med Sci. 2016;16:28-34.

28. Li Z, Tian T, Hu X, et al. Six 1 mediates resistance to paclitaxel in breast cancer cells. Biochem Biophys Res Commun. 2013;441:538-543.

29. Fuentes-Raspall MJ, Caragol I, Alonso C, et al. Apoptosis for prediction of radiotherapy late toxicity: lymphocyte subset sensitivity and potential effect of TP53 Arg72Pro polymorphism. Apoptosis. 2015;20:371-382.

30. Park SS, Kim YJ, Ju EJ, et al. Ibulocydine sensitizes human cancers to radiotherapy by induction of mitochondria-mediated apoptosis. Radiother Oncol. 2014;112:295-301.

31. Azria D, Ozsahin M, Kramar A, et al. Single nucleotide polymorphisms, apoptosis, and the development of severe late adverse effects after radiotherapy. Clin Cancer Res. 2008;14:6284-6288.

32. Ogawa T, Shiga K, Tateda M, et al. Protein expression of p53 and Bcl-2 has a strong correlation with radiation resistance of laryngeal squamous cell carcinoma but does not predict the radiation failure before treatment. Oncol Rep. 2003;10:1461-1466.

33. Mirkovic N, Voehringer DW, Story MD, McConkey DJ, McDonnell TJ, Meyn RE. Resistance to radiation-induced apoptosis in Bcl-2-expressing cells is reversed by depleting cellular thiols. Oncogene. 1997;15:1461-1470.

34. Guo W, Zhao YP, Jiang YG, Wang RW, Hong L, Fan DM. Upregulation of ZNRD1 enhances cisplatin resistance in human esophageal cancer cells by regulation of ERCC1 and Bcl-2. Tumour Biol. 2008;29: 188-194.

35. Qin Y, Zhang Q, Lee S, et al. Doxycycline reverses epithelial-tomesenchymal transition and suppresses the proliferation and metastasis of lung cancer cells. Oncotarget. 2015;6:40667-40679.

36. Li S, Li F, Niu R, et al. Mir-192 suppresses apoptosis and promotes proliferation in esophageal aquamous cell caicinoma by targeting Bim. Int J Clin Exp Pathol. 2015;8:8048-8056.

37. Watanabe H, Kurabayashi T, Miura M. Inhibition of the extracellular signal-regulated kinase (ERK) pathway and the induction of radioresistance in rat 3Y1 cells. Int J Radiat Biol. 2004;80:451-457.

38. Yuan L, Yi HM, Yi H, et al. Reduced RKIP enhances nasopharyngeal carcinoma radioresistance by increasing ERK and AKT activity. Oncotarget. 2016;7:11463-11477.

39. Shimura T, Noma N, Sano Y, et al. AKT-mediated enhanced aerobic glycolysis causes acquired radioresistance by human tumor cells. Radiother Oncol. 2014;112:302-307.

40. Ramalingam M, Kim SJ. Insulin involved Akt/ERK and Bcl-2/Bax pathways against oxidative damages in C6 glial cells. J Recept Signal Transduct Res. 2016;36:14-20.
OncoTargets and Therapy

\section{Publish your work in this journal}

OncoTargets and Therapy is an international, peer-reviewed, open access journal focusing on the pathological basis of all cancers, potential targets for therapy and treatment protocols employed to improve the management of cancer patients. The journal also focuses on the impact of management programs and new therapeutic agents and protocols on

\section{Dovepress}

patient perspectives such as quality of life, adherence and satisfaction. The manuscript management system is completely online and includes a very quick and fair peer-review system, which is all easy to use. Visit http://www.dovepress.com/testimonials.php to read real quotes from published authors. 